\title{
How initial tumor stage affects rectal cancer patient follow-up
}

\author{
KENICHI ODE ${ }^{1}$, UDAY PATEL ${ }^{2}$, KATHERINE S. VIRGO ${ }^{3,5}$, \\ RICCARDO A. AUDISIO ${ }^{4}$ and FRANK E. JOHNSON ${ }^{3,5}$
}

\author{
${ }^{1}$ Education Centre, Royal Lancaster Infirmary, Ashton Road, Lancaster LA1 4RR; ${ }^{2}$ St. George's Hospital \\ Medical School, University of London, Cranmer Terrace, London SW17 0RE, UK; ${ }^{3}$ Department of Surgery, \\ Saint Louis University Medical Center, 3635 Vista Ave., St. Louis, MO 63110, USA; ${ }^{4}$ Department of General Surgery, \\ Whiston Hospital - Prescot, Merseyside L35 5DR, UK; ${ }^{5}$ Department of Surgery, John Cochran \\ Veterans Affairs Medical Center, 915 North Grand Blvd., St. Louis, MO 63106, USA
}

Received November 4, 2008; Accepted December 19, 2008

DOI: 10.3892/or_00000382

\begin{abstract}
Many believe that follow-up testing for rectal carcinoma patients after primary curative-intent therapy should be rather intensive for high-stage lesions and less intensive for low-stage lesions. We recently carried out a survey of the American Society of Colon and Rectal Surgeons (ASCRS) to quantify the strategies they use after primary treatment for their own patients. Considerable variability in surveillance exists. Here we report how initial TNM stage affects follow-up intensity. We devised vignettes succinctly describing otherwise healthy patients with rectal carcinoma (stages I-III). We mailed a questionnaire based on the vignettes to the 1,795 ASCRS members. Responses deemed evaluable were entered into a computer database. The effect of TNM stage on follow-up intensity for patients with stage I, II, or III rectal carcinoma treated with radical surgery was assessed by repeated-measures ANOVA. The surveillance modality most frequently utilized was the office visit. In year 1 following surgery for patients with stage I lesions, $3.8 \pm 2.7$ office visits (mean $\pm \mathrm{SD}$ ) were recommended, decreasing to $1.5 \pm 1.0$ in year 5 . For patients with stage III lesions treated with radical surgery \pm adjuvant therapy, $4.0 \pm 2.8$ office visits were recommended in year 1 , decreasing to $1.7 \pm 1.2$ in year 5 . Similar results were generated for all commonly used surveillance modalities. The intensity of follow-up after curative-intent treatment for rectal carcinoma varies minimally across TNM stages. This suggests that a controlled trial comparing high-intensity versus low-intensity follow-up testing could be carried out without stratification by TNM stage.
\end{abstract}

Correspondence to: Dr Frank E. Johnson, Department of Surgery, Saint Louis University, 3635 Vista Avenue, St. Louis, MO 63110, USA

E-mail: frank.johnson1@va.gov

Key words: rectal cancer, follow-up, survey, American Society of Colon and Rectal Surgeons, tumor stage, controlled trial

\section{Introduction}

In 2002 there were 10.9 million new cases of cancer worldwide, including 1 million colorectal cancers (1). The first form of therapy to reliably achieve cure was excision. Goligher has summarized the fascinating history of surgery for rectal carcinoma (2). Miles devised the abdominoperineal resection and published his landmark paper in 1908 (3). The use of radiation was limited for most of the twentieth century but now plays an adjuvant role in most cases. Effective adjuvant chemotherapy is used in many patients as well. Refinements in treatment, advances in diagnosis, and improvements in supportive care have increased the five-year survival rate in the USA from $49 \%$ in 1975 to $66 \%$ at present (4). Similar statistics have been generated in other wealthy nations with good access to modern management. Many of the advances in diagnosis and management have been established through well-controlled trials. When well-designed adequately powered trials yield persuasive evidence favoring a particular strategy, efficiencies can result. For example, Mille et al reported a large decrease in the cost of breast cancer patient follow-up after the introduction of clinical practice guidelines which were based on a targeted literature review and a consensus of medical experts (5).

Post-treatment surveillance is anomalous in that few adequately powered controlled trials have been carried out to determine which strategy would be appropriate for a particular patient. Several studies of variable design have been reported, all of which are underpowered (6). A primary reason high-quality trials on this topic have been so rare is their expense, since large numbers of patients must be followed for several years to reach conclusions. Currently, therefore, clinicians, medical care systems, researchers, patients and others must rely on lower quality data to decide on surveillance schemes for patients after curative-intent therapy. There is corresponding variability among guidelines and in current practice (7).

About 41,000 people in the USA are diagnosed with rectal carcinoma each year (4). To achieve the current $66 \%$ fiveyear survival rate, perhaps $75 \%$ of the newly diagnosed patients, or 31,500, receive treatment with curative potential. Creating well-thought-out management strategies for these 
Table I. The four vignettes on which the survey was based.

1. A patient who has undergone local therapy (local excision, contact radiotherapy, cryosurgery) of a stage I (T1-2 N0 M0) rectal carcinoma.

2. A patient who has undergone radical surgery (proctectomy with colorectal or coloanal anastomosis or proctectomy with abdominoperineal resection) of a stage I (T1-2 N0 M0) rectal carcinoma.

3. A patient who has undergone radical surgery of a stage II (T3-4 N0 M0) rectal carcinoma.

4. A patient who has undergone radical surgery of a stage III (T1-4 N1-2 M0) rectal carcinoma.

patients has been identified as a major goal by the Institute of Medicine, the American Society of Clinical Oncology (ASCO), and other organizations (8). In an effort to further this goal, we surveyed members of the American Society of Colon and Rectal Surgeons (ASCRS) to determine how these highly experienced experts follow their own patients after completion of treatment. Not surprisingly, there was significant variation in follow-up intensity (7). We now report how much of this variation is ascribable to the initial stage of the tumor.

\section{Materials and methods}

There were 1,795 surveys mailed to the members of the ASCRS. This was followed by a second mailing to nonrespondents. A small sample (247) of the nonrespondents was contacted by email to determine the effectiveness of email as a tool to obtain increased response rates. However, this was not extended to the entire nonrespondent population due to the time involved and the low response rates (six responses).

The survey consisted of four components. The first part ascertained whether the surgeon was currently in practice, performing surgery, and personally conducting long-term postoperative follow-up for his own rectal cancer patients; those respondents answering affirmatively to these items were considered evaluable. All others were excluded. Respondents were then asked a series of questions regarding their age, training background, practice type, current medical society memberships, and other demographic variables.

The second part of the survey consisted of vignettes describing four otherwise healthy patients who had undergone uncomplicated surgery for rectal carcinoma (Table I). ASCRS members were asked to describe their follow-up schedule for each vignette by indicating the frequency per year with which they would recommend each diagnostic modality listed in the survey (Table II) during each of the first five years after initial therapy. Participants were also asked to list any other diagnostic modality that they use routinely and to state the recommended frequency, as for the other methods. In all scenarios, follow-up was defined as the period beginning with the completion of all adjuvant radiation theapy and/or chemotherapy. On receipt of the completed surveys, the data were entered into a computerized database (Statistical Package for the Social Services) and analyzed. The mean and standard deviation (SD) were calculated for each follow-up modality by stage and postoperative year. The hypothesis that surveillance varies by TNM stage was analyzed for the three scenarios in which radical surgery was described, using the general linear model of repeated-measures analysis of
Table II. The menu of follow-up modalities suggested in the questionnaire.

Office visit (including digital rectal examination, if indicated)

Complete blood count (CBC)

Liver function tests (LFTs)

Serum carcinoembryonic antigen (CEA) level

Colonoscopy

Flexible sigmoidoscopy

Chest radiograph

Intrarectal ultrasound

Computed tomography (CT) of abdomen/pelvis

CT of chest

Magnetic resonance imaging (MRI) of the abdomen/pelvis CEA scan (nuclear medicine)

Whole body positron emission tomography (PET) scan (fluorodeoxyglucose)

Bone scan (nuclear medicine)

Other

variance. The entire survey instrument is available on the Internet (http://surgery.slu.edu/survey/SurgerySurvey.pdf). Demographic data and results for local resection of stage I lesions are available elsewhere (7).

\section{Results}

Of the 1,782 surveys sent to the correct address, there were 566 responses (32\% response rate). Of these, 347/566 (61\%) filled out the survey correctly and were still actually providing care to rectal cancer patients (performing surgery and personally conducting follow-up). These 347 completed surveys were considered evaluable and were further analyzed.

The results of the survey showing the frequency of postoperative testing in years 1 to 5 for the three scenarios describing patients treated with radical surgery are summarized in Table III. The scenario dealing with transanal resection was not considered in this analysis. There were 246 respondents (71\%) who reported identical schedules for office visits across all tumor stages. Two hundred and twenty respondents $(63 \%)$ reported identical schedules for serum CEA level, 252 (73\%) 
Table III. Frequency of postoperative testing in years 1-5 for an otherwise healthy patient who has just undergone uncomplicated potentially curative radical surgery (proctectomy with colorectal or coloanal anastomosis or proctectomy by abdominoperineal resection) of stages I, II, or III rectal carcinoma $(n=343){ }^{\text {a }}$

\begin{tabular}{|c|c|c|c|c|}
\hline Modality & $\begin{array}{c}\text { Postoperative } \\
\text { year }\end{array}$ & $\begin{array}{c}\text { Stage I } \\
\text { mean } \pm \mathrm{SD}^{\mathrm{b}}\end{array}$ & $\begin{array}{c}\text { Stage II } \\
\text { mean } \pm \text { SD }\end{array}$ & $\begin{array}{c}\text { Stage III } \\
\text { mean } \pm \text { SD }\end{array}$ \\
\hline Office visit & $\begin{array}{l}1 \\
2 \\
3 \\
4 \\
5\end{array}$ & $\begin{array}{l}3.8 \pm 2.7 \\
3.2 \pm 2.7 \\
2.1 \pm 1.2 \\
1.7 \pm 1.0 \\
1.5 \pm 1.0\end{array}$ & $\begin{array}{l}3.9 \pm 2.7 \\
3.4 \pm 2.7 \\
2.3 \pm 1.3 \\
1.8 \pm 1.1 \\
1.6 \pm 1.1\end{array}$ & $\begin{array}{l}4.0 \pm 2.8 \\
3.5 \pm 2.8 \\
2.4 \pm 1.5 \\
1.9 \pm 1.2 \\
1.7 \pm 1.2\end{array}$ \\
\hline Serum CEA level ${ }^{c}$ & $\begin{array}{l}1 \\
2 \\
3 \\
4 \\
5\end{array}$ & $\begin{array}{l}2.9 \pm 2.8 \\
2.6 \pm 2.8 \\
1.8 \pm 1.9 \\
1.5 \pm 1.8 \\
1.3 \pm 1.8\end{array}$ & $\begin{array}{l}3.2 \pm 2.9 \\
2.9 \pm 2.8 \\
2.0 \pm 1.9 \\
1.7 \pm 1.8 \\
1.5 \pm 1.8\end{array}$ & $\begin{array}{l}3.3 \pm 2.9 \\
3.0 \pm 2.9 \\
2.1 \pm 1.9 \\
1.8 \pm 1.8 \\
1.6 \pm 1.8\end{array}$ \\
\hline $\mathrm{CBC}^{\mathrm{c}}$ & $\begin{array}{l}1 \\
2 \\
3 \\
4 \\
5\end{array}$ & $\begin{array}{l}1.4 \pm 2.8 \\
1.1 \pm 1.6 \\
0.8 \pm 1.3 \\
0.7 \pm 1.2 \\
0.7 \pm 1.1\end{array}$ & $\begin{array}{l}1.6 \pm 3.0 \\
1.2 \pm 1.6 \\
0.9 \pm 1.3 \\
0.8+1.2 \\
0.8 \pm 1.2\end{array}$ & $\begin{array}{l}1.6 \pm 3.0 \\
1.3 \pm 1.8 \\
1.0 \pm 1.5 \\
0.9 \pm 1.4 \\
0.8 \pm 1.4\end{array}$ \\
\hline Liver function tests & $\begin{array}{l}1 \\
2 \\
3 \\
4 \\
5\end{array}$ & $\begin{array}{l}1.3 \pm 2.8 \\
1.2 \pm 2.7 \\
0.8 \pm 1.9 \\
0.7 \pm 1.8 \\
0.7 \pm 1.1\end{array}$ & $\begin{array}{l}1.5 \pm 2.9 \\
1.3 \pm 2.8 \\
1.0 \pm 1.9 \\
0.8 \pm 1.8 \\
0.8 \pm 1.2\end{array}$ & $\begin{array}{l}1.6 \pm 3.0 \\
1.4 \pm 2.9 \\
1.1 \pm 2.0 \\
0.9 \pm 2.0 \\
0.8 \pm 1.3\end{array}$ \\
\hline Flexible sigmoidoscopy & $\begin{array}{l}1 \\
2 \\
3 \\
4 \\
5\end{array}$ & $\begin{array}{l}0.9 \pm 1.3 \\
0.8 \pm 1.2 \\
0.5 \pm 0.9 \\
0.4 \pm 0.7 \\
0.4 \pm 0.7\end{array}$ & $\begin{array}{l}0.9 \pm 1.4 \\
0.8 \pm 1.3 \\
0.6 \pm 0.9 \\
0.4 \pm 0.7 \\
0.4 \pm 0.7\end{array}$ & $\begin{array}{l}0.9 \pm 1.4 \\
0.9 \pm 1.3 \\
0.6 \pm 0.9 \\
0.4 \pm 0.7 \\
0.4 \pm 0.7\end{array}$ \\
\hline Chest radiograph & $\begin{array}{l}1 \\
2 \\
3 \\
4 \\
5\end{array}$ & $\begin{array}{l}0.8 \pm 0.9 \\
0.7 \pm 0.8 \\
0.6 \pm 0.7 \\
0.5 \pm 0.6 \\
0.5 \pm 0.6\end{array}$ & $\begin{array}{l}0.9 \pm 1.0 \\
0.8 \pm 0.9 \\
0.7 \pm 0.8 \\
0.5 \pm 0.6 \\
0.6 \pm 0.6\end{array}$ & $\begin{array}{l}1.0 \pm 1.0 \\
0.9 \pm 1.0 \\
0.7 \pm 0.8 \\
0.6 \pm 0.7 \\
0.7 \pm 0.7\end{array}$ \\
\hline Colonoscopy & $\begin{array}{l}1 \\
2 \\
3 \\
4 \\
5\end{array}$ & $\begin{array}{l}0.9 \pm 0.9 \\
0.5 \pm 0.7 \\
0.5 \pm 0.6 \\
0.6 \pm 1.0 \\
0.5 \pm 0.6\end{array}$ & $\begin{array}{l}0.9 \pm 0.9 \\
0.5 \pm 0.7 \\
0.5 \pm 0.6 \\
0.6 \pm 1.0 \\
0.5 \pm 0.6\end{array}$ & $\begin{array}{l}0.9 \pm 1.0 \\
0.5 \pm 0.7 \\
0.5 \pm 0.6 \\
0.6 \pm 1.0 \\
0.5 \pm 0.6\end{array}$ \\
\hline $\mathrm{CT}$ of abdomen and pelvis ${ }^{c}$ & $\begin{array}{l}1 \\
2 \\
3 \\
4 \\
5\end{array}$ & $\begin{array}{l}0.5 \pm 0.7 \\
0.4 \pm 0.6 \\
0.3 \pm 0.5 \\
0.2 \pm 0.5 \\
0.3 \pm 0.5\end{array}$ & $\begin{array}{l}0.6 \pm 0.7 \\
0.5 \pm 0.7 \\
0.4 \pm 0.6 \\
0.3 \pm 0.6 \\
0.3 \pm 0.6\end{array}$ & $\begin{array}{l}0.7 \pm 0.8 \\
0.6 \pm 0.8 \\
0.4 \pm 0.7 \\
0.3 \pm 0.6 \\
0.4 \pm 0.6\end{array}$ \\
\hline Intrarectal ultrasound & $\begin{array}{l}1 \\
2 \\
3 \\
4 \\
5\end{array}$ & $\begin{array}{l}0.4 \pm 0.9 \\
0.3 \pm 0.7 \\
0.2 \pm 0.6 \\
0.2 \pm 0.5 \\
0.2 \pm 0.5\end{array}$ & $\begin{array}{l}0.4 \pm 0.9 \\
0.3 \pm 0.8 \\
0.2 \pm 0.6 \\
0.2 \pm 0.5 \\
0.2 \pm 0.5\end{array}$ & $\begin{array}{l}0.4 \pm 0.9 \\
0.3 \pm 0.8 \\
0.3 \pm 0.6 \\
0.2 \pm 0.5 \\
0.2 \pm 0.5\end{array}$ \\
\hline CT of chest & $\begin{array}{l}1 \\
2 \\
3 \\
4 \\
5\end{array}$ & $\begin{array}{c}0.1 \pm 0.4 \\
0.1 \pm 0.4 \\
0.1 \pm 0.4 \\
0.1 \pm 0.3 \\
0.1 \pm 0.4\end{array}$ & $\begin{array}{l}0.1 \pm 0.5 \\
0.1 \pm 0.5 \\
0.1 \pm 0.4 \\
0.1 \pm 0.4 \\
0.1 \pm 0.4\end{array}$ & $\begin{array}{l}0.2 \pm 0.5 \\
0.1 \pm 0.5 \\
0.1 \pm 0.4 \\
0.1 \pm 0.4 \\
0.1 \pm 0.4\end{array}$ \\
\hline
\end{tabular}


Table III. Continued.

\begin{tabular}{|c|c|c|c|c|}
\hline Modality & $\begin{array}{c}\text { Postoperative } \\
\text { year }\end{array}$ & $\begin{array}{c}\text { Stage I } \\
\text { mean } \pm \mathrm{SD}^{\mathrm{b}}\end{array}$ & $\begin{array}{c}\text { Stage II } \\
\text { mean } \pm \text { SD }\end{array}$ & $\begin{array}{c}\text { Stage III } \\
\text { mean } \pm \text { SD }\end{array}$ \\
\hline MRI of abdomen and pelvis ${ }^{c}$ & $\begin{array}{l}1 \\
2 \\
3 \\
4 \\
5\end{array}$ & $\begin{array}{l}0.0 \pm 0.2 \\
0.0 \pm 0.2 \\
0.0 \pm 0.2 \\
0.0 \pm 0.1 \\
0.0 \pm 0.2\end{array}$ & $\begin{array}{l}0.0 \pm 0.2 \\
0.0 \pm 0.2 \\
0.0 \pm 0.2 \\
0.0 \pm 0.1 \\
0.0 \pm 0.2\end{array}$ & $\begin{array}{c}0.1 \pm 0.4 \\
0.1 \pm 0.4 \\
0.1 \pm 0.3 \\
0.0 \pm 0.2 \\
0.0 \pm 0.2\end{array}$ \\
\hline PET scan ${ }^{c}$ & $\begin{array}{l}1 \\
2 \\
3 \\
4 \\
5\end{array}$ & $\begin{array}{l}0.0 \pm 0.2 \\
0.0 \pm 0.1 \\
0.0 \pm 0.1 \\
0.0 \pm 0.1 \\
0.0 \pm 0.1\end{array}$ & $\begin{array}{l}0.1 \pm 0.2 \\
0.0 \pm 0.2 \\
0.0 \pm 0.1 \\
0.0 \pm 0.1 \\
0.0 \pm 0.1\end{array}$ & $\begin{array}{l}0.1 \pm 0.2 \\
0.0 \pm 0.2 \\
0.0 \pm 0.2 \\
0.0 \pm 0.1 \\
0.0 \pm 0.2\end{array}$ \\
\hline Bone scan & $\begin{array}{l}1 \\
2 \\
3 \\
4 \\
5\end{array}$ & $\begin{array}{l}0.0 \pm 0.1 \\
0.0 \pm 0.1 \\
0.0 \pm 0.2 \\
0.0 \pm 0.1 \\
0.0 \pm 0.1\end{array}$ & $\begin{array}{l}0.0 \pm 0.2 \\
0.0 \pm 0.1 \\
0.0 \pm 0.2 \\
0.0 \pm 0.1 \\
0.0 \pm 0.1\end{array}$ & $\begin{array}{l}0.0 \pm 0.2 \\
0.0 \pm 0.2 \\
0.0 \pm 0.2 \\
0.0 \pm 0.2 \\
0.0 \pm 0.2\end{array}$ \\
\hline CEA scan & $\begin{array}{l}1 \\
2 \\
3 \\
4 \\
5\end{array}$ & $\begin{array}{l}0.0 \pm 0.1 \\
0.0 \pm 0.1 \\
0.0 \pm 0.1 \\
0.0 \pm 0.1 \\
0.0 \pm 0.1\end{array}$ & $\begin{array}{l}0.0 \pm 0.1 \\
0.0 \pm 0.1 \\
0.0 \pm 0.1 \\
0.0 \pm 0.1 \\
0.0 \pm 0.1\end{array}$ & $\begin{array}{l}0.0 \pm 0.1 \\
0.0 \pm 0.1 \\
0.0 \pm 0.1 \\
0.0 \pm 0.1 \\
0.0 \pm 0.1\end{array}$ \\
\hline
\end{tabular}

${ }^{a}$ There were 347 responses to the 4 vignettes in the survey but only 343 completed the questionnaires dealing with the 3 vignettes analyzed in this report. ${ }^{b}$ Data shown are the mean $( \pm \mathrm{SD})$ of the number of visits or procedures, specific to each postoperative year, recommended by the respondents. ${ }^{\mathrm{c}} \mathrm{CEA}$, carcinoembryonic antigen; $\mathrm{CBC}$, complete blood count; $\mathrm{CT}$, computed tomography; MRI, magnetic resonance imaging; PET, positron emission tomography.

reported identical schedules for complete blood count (CBC), and $247(71 \%)$ used identical schedules for liver function tests (LFTs). These were the four most commonly used modalities. Correlation analysis revealed that surveillance patterns for most modalities were correlated highly $(r>0.70)$ across the years after surgery, indicating that the follow-up strategy for year 1 correlated highly with that in year 2, which correspondingly correlated with year 3 , etc. Therefore, the general linear model of repeated-measures analysis of variance was deemed appropriate for the purpose of this analysis.

The frequency of use of the various surveillance modalities in relation to the number of postoperative years was analyzed initially. There was sufficient power to detect a difference among years for 11 of the 14 modalities; office visit, serum CEA level, CBC, LFTs, flexible sigmoidoscopy, colonoscopy, chest radiograph, intrarectal ultrasound, CT of abdomen/ pelvis, CT of chest and PET scan. For all these modalities, there was a significant main effect $(\mathrm{p}<0.05$ for PET scan, $\mathrm{p}<0.01$ for all others); follow-up means generally decreased with increasing postoperative years. The three 'other' tests most commonly performed were proctoscopy $[n=15$ (stage I), $\mathrm{n}=14$ (stage II), $\mathrm{n}=14$ (stage III)], rigid sigmoidoscopy $[\mathrm{n}=15$ (stage I), n=16 (stage II), n=16 (stage III)], and abdominal ultrasound [ $\mathrm{n}=17$ (stage I), $\mathrm{n}=17$ (stage II), $\mathrm{n}=18$ (stage III)].

The data were then analyzed for differences among stages (stages I, II, III, radical resections). There was enough power to detect a statistically significant difference among stages for
12 of the 14 analyzed modalities. These modalities were office visit, serum CEA level, CBC, LFTs, flexible sigmoidoscopy, chest radiograph, intrarectal ultrasound, CT of abdomen/ pelvis, CT of chest, MRI of abdomen/pelvis, PET scan, and bone scan. For these modalities, a significant main effect of tumor stage was demonstrated, showing that higher tumor stage corresponded to a greater frequency of surveillance modality use $(\mathrm{p}<0.05$ for flexible sigmoidoscopy, intrarectal ultrasound and MRI; $\mathrm{p}<0.01$ for all others). The two modalities with power $<0.80$ were CEA scan and colonoscopy.

\section{Discussion}

O'Connell et al estimated that the overall five-year survival rate for patients with colon carcinoma was about $65 \%$ in 2004 in the US, and about 93\% for stage I (T1-2 N0 M0), $85 \%$ for stage II A (T3 N0 M0); $72 \%$ for stage II B (T4 N0 M0); $83 \%$ for stage III A (T1-2 N1 M0); $64 \%$ for stage III B (T3-4 N1 M0); 44\% for stage III C (any TN2 M0); and 8\% for stage IV (any T any NM1) in the US, using Surveillance Epidemiology and End Results (SEER) data (9). Extrapolation of these data to rectal cancer is accepted by the UICC (10). Since the survival rate is so good, many rectal cancer survivors receive surveillance following treatment. Some patients clearly benefit from this but the optimal surveillance strategy has not been defined by well-controlled, adequately powered clinical trials. Some of the benefits of post-treat- 
ment surveillance can be quantified. Anthony et al estimated that the increase in five-year survival rate ascribable to an organized surveillance regimen input to be as low as $0.3 \%$ or as high as $10 \%$ (11). There is substantial benefit in detecting recurrence of the index carcinoma, but few of these patients are cured. There is greater value when a second primary colorectal cancer is detected. The incidence of second primary invasive colorectal cancer after curative-intent treatment was approximately $0.3 \% / y e a r$ in a carefully studied clinical trial. Many of these are low-stage lesions and thus highly curable (12).

Surveillance programs also have collateral benefits (detecting an asymptomatic aortic aneurysm by $\mathrm{CT}$, for example) and harms (operative mortality following surgery for an asymptomatic aneurysm). There are difficult-to-quantify benefits of follow-up as well, such as the peace of mind that derives from being told that no abnormalities have been found on surveillance examinations. Some patients experience anxiety before test results are known. On balance, however, when cancer patients are queried about high-intensity surveillance as compared with low-intensity surveillance, they report equivalent quality of life and many prefer the low-intensity strategy (13).

Overuse, underuse, and misuse of scarce resources has been identified as an important societal problem (6), and rectal cancer patient care is a typical example. The cost-utility implications of the many recommended schemes for most disorders have not been carefully examined (14). Strategies in clinical medicine that maximize benefit for an individual patient often differ from those that maximize benefit for a population (15). A systematic review of the oncology literature indicates that our society is willing to pay for interventions that do not cost more than about $\$ 50,000$ per quality-adjusted life year gained by the intervention (16). For individuals without access to medical care, whether they are the underinsured or uninsured in the US or simply average citizens in poor nations, these figures are meaningless, of course, so decisions under these circumstances are heavily influenced by cost alone. For a physician practicing in an inner city clinic, obtaining a PET scan, for example, may take so much effort and involve so many bureaucratic hurdles that he or she simply does not attempt to order it, whereas a physician practicing in a wealthy area often finds that a patient can easily pay out-ofpocket for any surveillance test not covered by an insurance plan. Financial barriers to medical care and the resulting adverse effects on health have been amply documented elsewhere $(17,18)$. This undoubtedly contributes to the variation in medical practice in the US and, presumably, most other parts of the world. The end result is that variation in community standards of care at the neighborhood level is related primarily to the affluence of the residents of that microenvironment.

Sifting through the available evidence on rectal cancer patient follow-up is a large task for busy clinicians. Diagnostic tests should be carefully evaluated and the results reported; current evidence indicates that most evaluations are lacking in important dimensions, compromising their reliabilities and relevance (19). Guidelines created by trusted groups such as the National Cancer Center Network and ASCO are deservedly popular and regularly updated. They are limited by the quality of the evidence on which they are based, however, and the Institute of Medicine has estimated that only about four percent of clinical decision-making is strongly supported by evidence or consensus of experts (20). Guidelines should ideally have certain attributes: validity, an estimate of strength of available evidence, estimated outcomes, reliability, reproducibility, clinical applicability, clinical flexibility, and clarity. They should be created by a multidisciplinary process, undergo scheduled review, and the procedures used in guideline development should be documented and described. The medical review criteria should also possess particular attributes: sensitivity, specificity, responsiveness to patient preferences, and readability. They should be minimally obtrusive, feasible to obtain, easy to transform to computer protocols, and provide criteria for appeals by patients or professional caregivers. They should consider safety, cost, patient comfort, and accessibility to important modalities such as PET-CT fusion imaging. ASCO guidelines based on available evidence and expert opinion for surveillance after curative-intent therapy for colorectal cancer were first published in 1999 (21) and subsequently revised. Periodic history and directed physical examination, CEA testing, and colonoscopy are the only follow-up tests recommended. Electronic tools such as MEDLINE, CANCERLIT, and the Cochrane Library are also reliable, convenient, and increasingly user-friendly. The quality of the guideline development process is often seriously flawed, however (22). Making an optimal decision about interventions for a particular patient requires knowledge of potential outcomes and costs of various options. This helps a clinician to select interventions according to their costeffectiveness. Opting for the most cost-effective ones first, followed by others in the order of decreasing costeffectiveness, should promote optimal allocation of constrained resources at the level of the individual patient. Planners of industrial processes, after assigning appropriate values to relevant variables, are able to construct models to deliver the best outcomes for various input scenarios. Populations of patients, each with multiple clinical conditions and risk factors, pose much more complex decision-making problems.

This report concerns a large survey. Surveys typically provide data not available in any other way, although many weaknesses have been identified (23). The evidence shown here documents the self-reported recommendations of seasoned surgeons considering innumerable, often intangible aspects of patient care. The main conclusion of our analysis is that the TNM stage affects follow-up practice of ASCRS surgeons statistically significantly, but that the effect of stage is clinically trivial. This conclusion is congruent with an earlier survey that focused on follow-up for patients treated with curative intent for colon carcinoma (24). Few respondents to our survey selected diagnostic tests other than those presented in our questionnaire. This provides evidence that the survey instrument offered a comprehensive menu of modalities. Office visit is the most frequently employed diagnostic entity. Serum CEA level is the most frequently used blood test. Our data indicate, however, that $1 \%$ of ASCRS surgeons request serum CEA levels at least 12 times during the first postoperative year for rectal cancer patients with stage I-III 
Table IV. Proposed alternate trial arms of a clinical trial based on the survey results.

\begin{tabular}{lccc}
\hline Follow-up parameter & Postoperative year & More intensive strategy & Less intensive strategy \\
\hline Office visit & 1 & 6 per year & 3 per year \\
& $2-5$ & 4 per year & 2 per year \\
Serum CEA level & 1 & 6 per year & 3 per year \\
& $2-5$ & 4 per year & 2 per year \\
CT of abdomen and pelvis & 1 & 1 per year & 1 per year \\
& $2-5$ & 2 per year & 1 in year 3 only \\
Chest X-ray & 1 & 1 per year & 1 per year \\
& $2-5$ & 1 per year & 1 in year 3 only \\
Colonoscopy & 1 & 1 per year & 1 per year \\
\end{tabular}

lesions treated with curative-intent radical surgery, while $12 \%$ never request it. Colonoscopy and flexible sigmoidoscopy are both recommended regularly. Chest radiograph is the imaging study recommended most often, though CT is also used regularly. PET-CT fusion imaging was not available when the survey was mailed but seems likely to become an important modality.

The current report is the first to directly estimate the actual intensity of diagnostic testing after curative-intent surgery for rectal cancer, as delivered by practicing doctors who personally treat and follow these patients. The survey did not consider why ASCRS members order particular tests, how they acted on the test results, whether self-reported testordering frequency matches actual frequency, or whether the pattern of test ordering affects patient outcomes. We also point out that many rectal cancer patients undergo surgery by non-ASCRS surgeons and that follow-up may be delegated to medical oncologists, family physicians, or others. Their strategies may well differ from those described here. Our study was also limited by the relatively low response rate $(566 / 1782,32 \%)$, which may reflect the survey length. There were relatively few respondents from nations other than the USA $(144 / 566,25 \%)$ so our data do not permit reliable comparisons among countries. Despite these limitations, this report provides information not found elsewhere.

The specific and idealized situations presented in our questionnaire do not reflect all the elements of uncertainty present in actual practice. Nevertheless, 'standardized patient technology' is a validated and feasible method for measuring variability in clinical practice among physicians (25). We believe that this survey of a large sample of surgeons that used standardized patient vignettes provides an adequate approximation of actual practice. The results of this analysis do not permit us to comment on the value of different surveillance intensities for patients with different TNM stages since few data exist to document whether any strategy is beneficial, as measured by increased patient survival, quality of life, or cost-weighted parameters. It is worth recalling a highly cited definition of medical care quality: 'The best measure of quality is not how well or how frequently a medical service is given, but how closely the result approaches the fundamental objectives of prolonging life, relieving distress, restoring function, and preventing disability' (26).

Mullan, a cancer survivor who is also a practicing physician, is often credited with establishing cancer survivorship as a distinct entity, one deserving scholarly activity and general acceptance (27). He wrote that 'the challenge in overcoming cancer is not only to find therapies that will prevent or arrest the disease quickly, but also to map the middle ground of survivorship and minimize its medical and social hazards'. There are now over 10 million cancer survivors in the US and this number is constantly increasing because of advances in cancer detection and treatment. Comparable statistics are generated in virtually all western industrial societies. Acceptance of the concept of cancer survivorship and research dealing with the topic have generated notice. Public policy has flowed from this. The 2004 report of the President's Cancer Panel (28), the 2004 National Action Plan for Cancer Survivorship of the Lance Armstrong Foundation and the Centers for Disease Control and Prevention (29), and the 2006 Analysis of the Institute of Medicine (8) all called for increased research to promote the well-being of cancer survivors. Numerous consumer advocacy groups such as the National Coalition for Cancer Survivorship have labored to generate community support and legislation to further these goals (30).

We used data from our survey to devise two surveillance strategies, one somewhat more intensive than the mean and one somewhat less intensive (Table IV). These would be good candidates for a randomized clinical trial since both are representative of the self-reported actual practices of ASCRS members. Such trials are feasible, although they are expensive and difficult to perform. Although most surgeons follow their own rectal cancer patients after surgery (7), carefully conducted trials indicate that patient follow-up for several common types of cancer can be carried out successfully by general practitioners as well as surgeons $(31,32)$. The lack of uniformity in surveillance is not confined to surgeons or medical oncologists (33). It extends to general internal medicine physicians caring for patients with other common chronic disorders (34). It is also related to patient expectations. The public is quite enthusiastic about screening for cancer, 
for example (35). The eventual financial gains from wellcontrolled, adequately powered trials have been projected to outweigh costs by $1-2$ orders of magnitude $(36,37)$. Such trials directed at patients with rectal cancer after curativeintent treatment are in progress now (6). The eventual results should provide high-quality evidence on which clinicians can base their own practice. The optimal strategy for individual patients may well vary because of cultural differences, personal preferences, financial considerations and other factors (38).

\section{Acknowledgements}

There was no financial support for this work from any external funding source. This study was presented in abstract form at the 2007 Annual Meeting of the Society of Surgical Oncology, the 2007 Annual Meeting of the Association for Academic Surgery, and the 2007 Annual Meeting of ASCO.

\section{References}

1. Parkin DM, Bray F, Ferlay J and Pisani P. Global cancer statistics, 2002. CA Cancer J Clin 55: 74-108, 2005.

2. Goligher JC: Treatment of carcinoma of the rectum. In: Surgery of the Anus, Rectum and Colon. Goligher JC (ed). 4th edition. Balliere Tindall, London, pp502-667, 1980.

3. Miles WE: A method of performing abdominoperineal excision for carcinoma of the rectum and of the terminal portion of the pelvic colon. Lancet 2: 1812, 1908 .

4. Jemal A, Siegel R, Ward E, Murray T, Xu J and Thun MJ: Cancer Statistics, 2007. CA Cancer J Clin 57: 43-66, 2007.

5. Mille D, Roy T, Carrere M, et al: Economic impact of harmonizing medical practices: compliance with clinical practice guidelines in the follow-up of breast cancer in a French Comprehensive Cancer Center. J Clin Oncol 18: 1718-1724, 2000.

6. Johnson FE, Virgo KS and Fossati R: Follow-up for patients with colorectal cancer after curative-intent primary treatment. J Clin Oncol 22: 1363-1365, 2004

7. Johnson FE, Longo WE, Ode K, et al: Patient surveillance after curative-intent surgery for rectal cancer. Int J Oncol 27: 815-822, 2005

8. Hewitt M, Greenfield S, Stovall E (eds): From Cancer Patient to Cancer Survivor: Lost in Transition. The National Academies Press, Washington, D.C., 2006.

9. O'Connell JB, Maggard MA and Ko CY: Colon cancer survival rates with the new American Joint Committee on Cancer sixth edition staging. J Natl Cancer Inst 96: 1420-1425, 2004.

10. Gil-Delgado MA, Khayat D and Taieb J: Cancer of the colon and rectum. In: International Union Against Cancer (UICC), Manual of Clinical Oncology. Pollock RE, Doroshow JH, Khayat D, Nakao A, O'Sullivan B (eds). 8th edition, WikleyLiss, Hoboken, p494, 2004.

11. Anthony T, Fleming JB, Bieligk SC, et al: Postoperative colorectal cancer surveillance. J Am Coll Surg 190: 737-749, 2000.

12. Green RJ, Metlay JP, Propert K, et al: Surveillance for second primary colorectal cancer after adjuvant chemotherapy: an analysis of intergroup 0089. Ann Intern Med 136: 261-269, 2002.

13. Gulliford T, Opomu M, Wilson E, Hanham I and Epstein R: Popularity of less frequent follow up for breast cancer in randomised study: initial findings from the hotline study. BMJ 314: 174-177, 1997.

14. Johnson FE and Virgo KS: Cancer Patient Follow-Up. Mosby, St. Louis, 1997.
15. Granata AV and Hillman AL: Competing practice guidelines: using cost-effectiveness analysis to make optimal decisions. Ann Intern Med 128: 56-63, 1998.

16. Earle CC, Chapman RH, Baker CS, et al: Systematic overview of cost-utility assessments in oncology. J Clin Oncol 18: 3302-3317, 2000.

17. Rahimi AR, Spertus JA, Reid KJ, Bernheim SM and Krumholz HM: Financial barriers to health care and outcomes after acute myocardial infarction. JAMA 297: 1063-1072, 2007.

18. Bach PB, Phamm HH, Schrag D, Tate RC and Hargraves JL: Primary care physicians who treat blacks and whites. N Engl J Med 351: 575-584, 2004.

19. Mallett S, Deeks JJ, Halligan S, Hopewell S, Cornelius V and Altman DA: Systematic review of diagnostic tests in cancer: review of methods and reporting. BMJ 333: 413, 2006.

20. Field MJ and Lohr KN (eds): Guidelines for Clinical Practice: From Development to Use. National Academy Press, Washington, D.C., p34, 1992.

21. Desch CE, Benson AB, Somerfield MR, et al: Colorectal cancer surveillance: 2005 update of an American Society of Clinical Oncology practice guideline. J Clin Oncol 23: 8512-8519, 2005.

22. Grilli R, Magrini N, Penna A, Mura G and Liberati A: Practice guidelines developed by specialty societies: the need for a critical appraisal. Lancet 355: 103-106, 2000.

23. Chitwood WR: National surveys: Are they helpful? Ann Thorac Surg 59: 275-276, 1995.

24. Johnson FE, Longo WE, Vernava AM, Wade TP, Coplin MA and Virgo KS: How tumor stage affects surgeons' surveillance strategies after colon cancer surgery. Cancer 76: 1325-1329, 1995.

25. McLeod PJ, Tamblyn RM, Gayton D, et al: Use of standardized patients to assess between-physician variations in resource utilization. JAMA 278: 1164-1168, 1997.

26. Lembcke PA: Measuring the quality of medical care through vital statistics based on hospital service areas: I. Comparative study of appendectomy rates. Am J Public Health Nations Health 42: 276-286, 1952

27. Mullan F: Seasons of survival: Reflections of a physician with cancer. N Eng J Med 313: 270-273 1985.

28. President's Cancer Panel: Living Beyond Cancer: Finding a New Balance. National Cancer Institute, Bethesda, US Department of Health and Human Services, 2004.

29. Center for Disease Control and Prevention and Lance Armstrong Foundation joint publication, 2004. National Action Plan for Cancer Survivorship: Advancing Public Health Strategies.

30. Clark EJ, Stovall EL, Leigh S, et al: National Coalition for Cancer Survivorship. Imperatives for Quality Cancer Care: Access, Advocacy, Action, and Accountability. NCCS, Silver Spring, 1996.

31. Wattchow DA, Weller DP, Esterman A, et al: General practice vs. surgical-based follow-up for patients with colon cancer: randomised controlled trial. Br J Cancer 94: 1116-1121, 2006.

32. Grunfeld E, Mant D, Yudkin P, et al: Routine follow-up of breast cancer in primary care: randomized trial. BMJ 313: 665-669, 1996.

33. Richert-Boe KE: Heterogeneity of cancer surveillance practices among medical oncologists in Washington and Oregon. Cancer 75: 2605-2612, 1995

34. Schwartz LM, Woloshin S, Wasson JH, Renfrew RA and Welch HG: Setting the revisit interval in primary care. J Gen Intern Med 14: 230-235, 1999.

35. Schwartz LM, Woloshin S, Fowler FJ Jr and Welch HG: Enthusiasm for cancer screening in the United States. JAMA 291: 71-78, 2004.

36. Phelps CE and Parente ST: Priority setting in medical technology and medical practice assessment. Med Care 28: 703-723, 1990.

37. Phelps CE and Mooney C: Correction and update on 'Priority setting in medical technology and medical practice assessment.' Med Care 30: 744-751, 1992.

38. Loprinzi CL, Hayes D and Smith T: Doc, shouldn't we be getting some tests? J Clin Oncol 18: 2345-2348, 2000. 